\title{
Epidemiology and Risk Factors of Tooth Loss among Iranian Adults: Findings from a Large Community-Based Study
}

\author{
Saber Khazaei, ${ }^{1}$ A. H. Keshteli, ${ }^{2,3}$ Awat Feizi, ${ }^{4}$ \\ Omid Savabi, ${ }^{5}$ and Peyman Adibi ${ }^{3}$ \\ ${ }^{1}$ Dental Students' Research Center, Isfahan University of Medical Sciences, Isfahan 81749-73461, Iran \\ ${ }^{2}$ Department of Medicine, University of Alberta, Edmonton, AB, Canada T6G $2 E 1$ \\ ${ }^{3}$ Integrative Functional Gastroenterology Research Center, Isfahan University of Medical Sciences, Isfahan 81749-73461, Iran \\ ${ }^{4}$ Department of Biostatistics and Epidemiology, School of Public Health, Isfahan University of Medical Sciences, Hezar Jarib Street, \\ Isfahan 81749-73461, Iran \\ ${ }^{5}$ Department of Prosthodontics, Torabinejad Dental Research Center, School of Dentistry, Isfahan University of Medical Sciences, \\ Isfahan 81749-73461, Iran \\ Correspondence should be addressed to Awat Feizi; awat_feiz@hlth.mui.ac.ir
}

Received 13 June 2013; Revised 25 August 2013; Accepted 29 August 2013

Academic Editor: Sabine Rohrmann

Copyright (C) 2013 Saber Khazaei et al. This is an open access article distributed under the Creative Commons Attribution License, which permits unrestricted use, distribution, and reproduction in any medium, provided the original work is properly cited.

\begin{abstract}
Objectives. To investigate the prevalence of tooth loss and different prosthetic rehabilitations among Iranian adults, as well as the potential determinants of tooth loss. Methods. In a cross-sectional community-based study conducted among 8094 Iranian adults living in Isfahan province, a self-administered questionnaire was used to assess epidemiologic features of tooth loss. Results. Thirtytwo percent of subjects had all their teeth, 58.6\% had lost less than 6, and 7.2\% of participants had lost more than 6 teeth. One hundred and sixty-nine individuals (2.2\%) were edentulous. Among participants, $2.3 \%$ had single jaw removable partial denture, $3.6 \%$ had complete removable denture in both jaws, and $4.6 \%$ had fixed prosthesis. Others reported no prosthetic rehabilitation (89.5\%). In the age subgroup analysis ( $\leq 35$ and $>35$ years old) tooth loss was more prevalent among men than women (OR $=2.8$ and 1.9, resp., $P<0.01)$. Also, in both age groups, current and former smokers had higher levels of tooth loss than nonsmokers $(P<$ 0.001 and $P<0.05$, resp.). In addition, tooth loss was positively related to metabolic abnormality for age group $>35$ years (adjusted $\mathrm{OR}=1.29, P<0.01)$. Conclusions. Tooth loss is highly prevalent in Iranian adult population. Community programs promoting oral health for prevention of tooth loss should be considered taking into account its major determinants including lower educational level, male gender, smoking, and metabolic abnormality.
\end{abstract}

\section{Introduction}

Tooth loss is known to have an essential role in the loss of mastication and esthetics [1]. Worldwide, the prevalence of tooth loss and edentulism is high and depends on many factors [2-4]. Prevalence of tooth loss and edentulism is high in Iran [5]. The prevalence of edentulism was reported to be about $3 \%$ among $35-44$-year-old Iranians, while $22 \%$ of subjects had less than 20 teeth [6].

Food choice, diet, and nutrition intake can be influenced by the number and condition of teeth [1]. Inadequate dentition can cause problems in food intake; it will affect mastication, and masticatory abilities have been known to play an important role in digestive system and overall health condition [1]. Complete edentulous people were found to be at a higher risk of poor nutrition and weak chewing ability [7].

According to the World Health Organization (WHO), adults should have a minimum of 21 functional teeth to provide the ability to experience a good dietary intake without the need for dentures [8]. It has been shown that edentulism considerably reduces the quality of life [9]. Slade and Spencer [10] reported that compared to dentate people, edentulous ones experienced more social and psychological impacts on their quality of life including feeling self-conscious and avoiding social interactions. Also, edentulous subjects reported 
to experience more pain and discomfort and had frequent difficulties with chewing and eating [10].

Social-behavioral risk indicators may play a substantial role in edentulism. Potential risk factors for edentulism are low level of education, older age, gender, and marital status [11]. Burt et al. [12] evaluated risk factors of tooth loss over a period of 28 years and found that the effect of socialbehavioral risk factors was more evident in the complete edentulous individuals compared to the group with partial edentulism. Low income has also been suggested to be a risk factor for edentulism [13, 14]. Caries experience, attachment loss, and cigarette smoking are other major risk indicators of tooth loss $[15,16]$. In addition, patterns of tooth loss vary by gender and population $[11,16]$.

The major purpose of dental restorations is to replace missing teeth. A restoration is the general term for any material or prosthesis that replaces the lost tooth structure, teeth, or oral tissues [3]. Dental restorations are fixed or removable and are termed fixed restorations and removable dental prosthesis. The removable dental prostheses are also classified into removable partial denture and complete denture [3]. Based on previous studies, social and geographical variations in prosthetic replacement may be related to differences in both patients' and dentists' attitudes towards oral health as well as socioeconomic status [13, 17-19].

To our knowledge, data on the prevalence of tooth loss and its risk factors and prosthetic rehabilitation according to sociodemographic information and the prevalence of each type are sparse, particularly in Iran [6]. Previous studies among Iranian population showed a high rate of tooth loss and edentulism $[3,5,6]$, and tooth loss-related risk factors have not been evaluated in a community-based survey. Therefore, the aim of the present study was to investigate the epidemiology of tooth loss and its related social-behavioral factors and to assess the prevalence of different prosthetic rehabilitation among a large sample of Iranian adults.

\section{Materials and Methods}

2.1. Study Design and Population. This project is a part of the "Study on the Epidemiology of Psychological, Alimentary Health and Nutrition" (SEPAHAN) [20]. In this cross-sectional study, staffs of Isfahan University of Medical Sciences (IUMS) working in university campus, hospitals, and health centers across the Isfahan province were included. In the first phase of SEPAHAN, 8094 participants completed selfadministered questionnaires about demographic information, medical history, anthropometric measures, lifestyle, and nutritional factors, as well as dental status (average response rate for all questionnaires: $86.16 \%$ and response rate for dental questions: $97.5 \%$ ). Detailed information about the project has been provided elsewhere [20].

2.2. Ethical Approval. This study approved by the Regional Bioethics Committee of Isfahan Province (numbers 189069, 189082, and 189086) and was conducted in accordance with the national and international codes.
2.3. Assessment of Studied Variables. Questions were selected from standard questionnaires that were previously validated in Iranian settings. However, we had to design some new assessment tools or translate some questions into Persian using the forward and back-translation procedure. The face and content validity of the final questionnaire was evaluated [20].

2.4. Main Variables (Tooth Loss and Restorative Replacement). There were some questions to assess tooth loss, presence of edentulism, and the type of restorative replacement, if present. Edentulism was defined as subjects with "no remaining teeth." Partial tooth loss was categorized into two subcategories: (1) less than 6 lost teeth and (2) 6 or more lost teeth. The following four categories were considered regarding the restorative replacement: (1) without any prosthesis, (2) single jaw removable partial dentures, (3) complete removable denture in both jaws, and (4) fixed prosthesis.

2.5. Other Variables. The information about age, gender, weight, and height was provided by self-administered questionnaires. Body mass index (BMI) was calculated by dividing weight in kilograms by height in meters squared. Based on self-reported data on smoking habits subjects were categorized as nonsmokers, former smokers, or current smokers. Also they were categorized as diploma (12 years formal education) and lower, bachelor, master, or doctorate based on educational attainments. Self-reported history of any predisposing chronic diseases including diabetes mellitus, hypertension, and hyperlipidemia was explored. A binary variable referred to as "metabolic abnormality" was considered to be present when a subject's BMI was $\geq 30$ or he/she reported to have at least one of the followings: diabetes mellitus, hypertension, or hyperlipidemia.

2.6. Statistical Analysis. Quantitative and qualitative variables were represented as mean \pm SD and number (percent), respectively. To investigate the relationship between qualitative risk factors and levels of tooth loss, chi-square test were used as a univariate method. Multinomial logistic regressions was used as the multivariable method to investigate the association between levels of tooth loss (as dependent variable), age, educational attainment, sex, smoking habits, and metabolic abnormality as the potential determinants. Also, age stratified analysis ( $\leq 35$ and $>35$ years old) was done using binary logistic regression for evaluating the association between tooth loss and educational attainment, sex, smoking habits, and metabolic abnormality. To compare the quantitative variables across the levels of tooth loss, one-way analysis of variance (one-way ANOVA) was conducted. All statistical analyses were performed using SPSS version 16 (SPSS Corp., Chicago, IL, USA), and $P$ value less than 0.05 was considered statistically significant.

\section{Results}

Out of 7893 respondents, 3338 (42.3\%) were male and 4555 $(57.7 \%)$ were female. The mean age was $37.02 \pm 8.1$ years with 
range of 19 to 75 years. Overall, 2512 (32\%) of subjects had all their teeth, 4603 (58.6\%) had less than 6 lost teeth, and 556 (7.2\%) had 6 or more lost teeth. One hundred and sixty-nine (2.2\%) individuals were edentulous. Among 7654 studied participants who responded to the prosthetic rehabilitation question, $2.3 \%$ had single jaw removable partial denture, $3.6 \%$ had complete removable denture in both jaws, and $4.6 \%$ had fixed prosthesis. Others reported no prosthetic rehabilitation (89.5\%). Among the edentulous subjects, $2.5 \%$ had single jaw removable partial denture, $87 \%$ had complete removable denture in both jaws, $6.2 \%$ had implant supported fixed prosthesis, and only $4.3 \%$ of them were without dentures. Table 1 shows the distribution of number of missing teeth across different age groups in the study population. Subjects in the upper categories of age were more likely to be edentulous or have more number of missing teeth $(P<0.0001)$.

Tooth loss and edentulism were significantly more common in males than in females $(P<0.0001)$. Current smokers and those suffering from chronic diseases such as diabetes, hypertension, or hyperlipidemia were more likely to have higher number of tooth loss $(P<0.0001)$. In addition, less educated people were more likely for being in higher levels of tooth loss. There were significant differences between tooth loss groups in terms of age and BMI, in which those with higher levels of tooth loss had significantly higher BMI and were older $(P<0.0001)$ (Table 2$)$.

Tooth loss and edentulism were more prevalent among current and former smokers $(P<0.0001)$. Logistic regression analysis showed that the nonsmokers were more likely to have all their teeth (adjusted OR $=12.8,95 \%$ CI: 6.78-24.16, $P<$ 0.0001 ), while men and less educated participants were less likely to have all teeth or lower levels of tooth loss. Age was negatively associated with lower levels of tooth loss (Table 3).

The results of multivariable logistic regression stratified based on two age groups ( $\leq 35$ and $>35$ years old) are presented in Table 4 . In both age groups, smoking and male gender were associated with increased risk of tooth loss. Also, in subjects who were above 35 years old, participants with metabolic abnormality were at 29\% increased risk of losing 6 or more teeth (adjusted OR: 1.29, 95\% CI: 1.07-1.59, $P<0.01$ ) (Table 4).

\section{Discussion}

In this large cross-sectional community-based study in Iran, the prevalence of tooth loss was found to be high among the study population. Only one-third of the population did not experience tooth loss, whereas about one-tenth of participants showed significant loss (over 6 lost teeth). Also, the prevalence of edentulism was found to be $2.2 \%$.

Various prevalence rates of tooth loss have been reported around the world. Based on Swiss Health Survey among 14326 subjects, the prevalence of edentulism was $0.3 \%$ and $26.8 \%$ in 15-24-and 65-74-year-old subjects, respectively [21]. According to a systematic review conducted in Iran, the prevalence rate of tooth loss varied from $0.3 \%$ in 3-5 yearold children to $70.7 \%$ in adults older than 65 [5]. In a large population-based study among 35-44-year-old Iranians, the prevalence of edentulism was estimated to be $3 \%$ [6]. In a study carried out among 1545 Turkish elderly, the prevalence of edentulism was $48 \%$ [22]. A systematic review of 73 studies in Europe showed that, in many European countries, edentulism is already rare among people of working age or up to 60 years of age, whereas there are still many edentulous subjects in the age group above 65-in studies from the 1990s, the prevalence varied between $15 \%$ and $72 \%$ [11].

In contrast to several studies, the present study showed that the tooth loss and edentulism were more prevalent in males $[6,11,23]$. It has been discussed that the greater importance of esthetics among women may be associated with higher rate of edentulism [5]. The high prevalence rate of tooth loss and edentulism among men seems to be dental disease-related such as dental caries, periodontal disease, trauma, infection, and sociobehavioral including smoking and poor oral hygiene. Many studies indicated that tooth loss and edentulism are positively associated with aging, which is similar to the results of the present study $[5,11,24,25]$. Periodontitis is one of the major risk factors of tooth loss [26], and the prevalence of periodontitis is increased by aging [25]. This can be considered as logical item in aging-related tooth loss.

Previous studies have indicated that cigarette smokers are more inclined to missing teeth and edentulism [27-29]. Dental caries are more prevalent in smokers which may result in loss of teeth [30]. Ojima et al. [31] reported a significant positive exposure-related relationship between smoking and the rate of tooth loss. Axelsson et al. [27] demonstrated a significant larger number of decay and filled teeth among smokers than nonsmokers. In a cross-sectional study among 1002 Japanese young adult women, a positive association was reported between active smoking and tooth loss [32]. A study in Finnish population reported a significant relationship between smoking and loss of six or more teeth, which was similar to our study [33]. Furthermore, Dietrich et al. [34] reported that cigarette smoking was strongly associated with a dose-dependent increase in the risk for incident tooth loss among male health professionals. Saliva has an important effect on the maintenance of oral health and buffers the acids when produced. Saliva also plays an important role in self-cleansing of the teeth and physically removes debris from tooth surfaces. In addition, it has immunological and bacteriostatic properties $[35,36]$. Heintze [37] demonstrated that for cigarette smokers, the buffering capacity of saliva was substantially lower than nonsmokers and that the number of Lactobacilli and Streptococcus mutans was significantly higher in saliva of smokers than nonsmokers. The decrease in the buffering capacity of saliva and increase in the level of cariogenic bacteria result in high incidence of caries in smokers, which eventually leads to tooth loss. In the present study, we demonstrated that cigarette smoking can be considered as a risk factor of tooth loss and edentulism. It should be noted that the prevalence of smoking in the study population was much lower than its prevalence in Isfahan province. The study population of the present study consisted of a medical university staff with higher educational level than the Iranian general population, and it has been shown that university educational level was shown to be inversely related to smoking in Isfahan [38]. 
TABLE 1: Distribution of the number of missing teeth across the different age groups.

\begin{tabular}{|c|c|c|c|c|}
\hline \multirow{2}{*}{ Age group } & \multicolumn{4}{|c|}{ Number (\%) of lost teeth } \\
\hline & 0 & $<6$ & $\geq 6$ & Edentulous \\
\hline $19-24$ & $182(61.3)$ & $113(38.8)$ & $2(7)$ & $0(0)$ \\
\hline $25-29$ & $639(54.2)$ & $538(45.6)$ & $2(2)$ & $0(0)$ \\
\hline $30-34$ & $608(39.9)$ & $874(57.4)$ & $38(2.5)$ & $3(2)$ \\
\hline $35-39$ & $412(27.7)$ & $986(66.1)$ & $78(5.2)$ & $15(1)$ \\
\hline $40-44$ & $294(21.7)$ & $888(65.5)$ & $139(10.3)$ & $35(2.6)$ \\
\hline $45-49$ & $125(15.9)$ & $497(63.3)$ & $121(15.4)$ & $42(5.4)$ \\
\hline $50+$ & $80(13.1)$ & $336(55.3)$ & $122(20.1)$ & $70(11.5)$ \\
\hline
\end{tabular}

TABLE 2: Distribution of the number of missing teeth across different categories of demographic and clinical characteristics.

\begin{tabular}{|c|c|c|c|c|c|}
\hline \multirow{2}{*}{ Characteristics } & \multicolumn{4}{|c|}{ Number of lost teeth } & \\
\hline & 0 & $<6$ & $\geq 6$ & Edentulism & \\
\hline \multicolumn{6}{|l|}{ Sex } \\
\hline Male & $726(22.6 \%)$ & 1997 (61.5\%) & $370(11.5 \%)$ & $142(4.4 \%)$ & \multirow{2}{*}{$P<0.001^{\mathrm{a}}$} \\
\hline Female & $1712(38.5 \%)$ & $2522(56.7 \%)$ & $187(4.2 \%)$ & $25(0.6 \%)$ & \\
\hline Age & $33.3 \pm 7.3$ & $37.7 \pm 7.7$ & $44.0 \pm 6.8$ & $47.9 \pm 6.9$ & $P<0.001^{\mathrm{b}}$ \\
\hline \multicolumn{6}{|l|}{ Education } \\
\hline Diploma and lower & $640(19.8 \%)$ & $2029(63 \%)$ & $414(12.9 \%)$ & $137(4.3 \%)$ & \multirow{3}{*}{$P<0.001^{\mathrm{a}}$} \\
\hline Bachelor & $1556(40.3 \%)$ & $2169(56.1 \%)$ & $118(3.1 \%)$ & $21(0.5 \%)$ & \\
\hline Master and doctorate & $274(45.4 \%)$ & $316(52.2 \%)$ & $13(2.1 \%)$ & $2(0.3 \%)$ & \\
\hline Body mass index & $24.4 \pm 7.7$ & $25.3 \pm 4.1$ & $25.8 \pm 4.3$ & $25.8 \pm 4.7$ & $P<0.001^{\mathrm{b}}$ \\
\hline \multicolumn{6}{|l|}{ Smoking } \\
\hline Former smokers & $38(10.7 \%)$ & $209(58.9 \%)$ & $81(22.8 \%)$ & $27(7.6 \%)$ & \multirow{3}{*}{$P<0.001^{\mathrm{a}}$} \\
\hline Nonsmokers & $2154(34.5 \%)$ & 3697 (59.2\%) & $327(5.2 \%)$ & $68(1.1 \%)$ & \\
\hline Smokers & $27(8.7 \%)$ & $148(47.9 \%)$ & $75(24.3 \%)$ & $59(19.1 \%)$ & \\
\hline \multicolumn{6}{|l|}{ Hyperlipidemia } \\
\hline Yes & $134(20.8 \%)$ & $414(64.2 \%)$ & $76(11.8 \%)$ & $21(3.3 \%)$ & \multirow{2}{*}{$P<0.001^{\mathrm{a}}$} \\
\hline No & $2378(33 \%)$ & $4189(58.1 \%)$ & $490(6.8 \%)$ & $148(2.1 \%)$ & \\
\hline \multicolumn{6}{|l|}{ Hypertension } \\
\hline Yes & $56(19.2 \%)$ & $190(65.1 \%)$ & $35(12 \%)$ & $11(3.8 \%)$ & \multirow{2}{*}{$P<0.001^{\mathrm{a}}$} \\
\hline No & $2456(32.5 \%)$ & $4413(58.4 \%)$ & $531(7 \%)$ & $158(2.1 \%)$ & \\
\hline \multicolumn{6}{|l|}{ Diabetes mellitus } \\
\hline Yes & $27(16.3 \%)$ & $104(62.7 \%)$ & $28(16.9 \%)$ & $7(4.2 \%)$ & \multirow{2}{*}{$P<0.001^{\mathrm{a}}$} \\
\hline No & $2485(32.3 \%)$ & $4499(58.6 \%)$ & $538(7 \%)$ & $162(2.1 \%)$ & \\
\hline
\end{tabular}

${ }^{\mathrm{a}}$ Chi-square test.

${ }^{\mathrm{b}}$ One-way ANOVA.

In the present study, we found a positive relationship between tooth loss and BMI. It has been suggested that the number of teeth may have an effect on BMI [39]. Conflicting results have been reported regarding the relationship between number of teeth and BMI. In several studies lower intake of recommended nutrients has been reported in edentate subjects in comparison to dentate subjects [40-42]. Sheiham and Steele [1] reported that having any number of remaining teeth is better than having none when comparing the nutrient intake of individuals with very few teeth as opposed to edentulous subjects. Having at least 20 teeth or more helps the intake of nutrients, prevention of underweight and overweight conditions, and prevention of abnormal BMI [8]. Ostberg et al. [43] found statistically significant associations between a small number of teeth (less than 20) and BMI, waist-hip ratio, and waist circumference as different indicators of obesity. However, it should be noted that prosthetic replacement of lost teeth does not necessarily guarantee the prevention of undesired BMI. In a study conducted by Hilgert et al. [44] partial or complete tooth loss not being replaced with prosthetics was in relation with obesity.

In the present study, a binary variable referred to as "metabolic abnormality" was created when at least one of these four conditions was present: diabetes mellitus, hypertension, hyperlipidemia, or obesity $(\mathrm{BMI} \geq 30)$. The results showed that subjects with metabolic abnormality were more prone to have higher level of tooth loss and being edentulism. Diabetes mellitus has been known as a risk factor for 


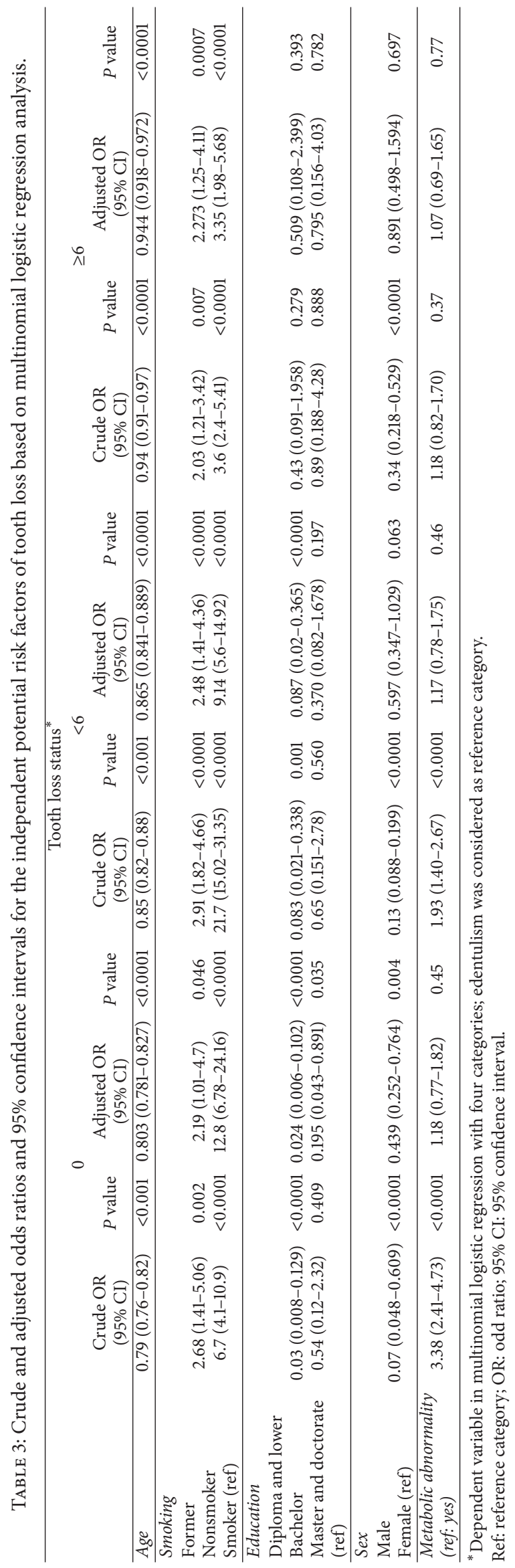


TABLE 4: Age stratified analysis of association between tooth $\operatorname{loss}^{1}$ and metabolic abnormality, smoking, and gender.

\begin{tabular}{|c|c|c|c|c|}
\hline \multirow[t]{2}{*}{ Independent variables } & $\begin{array}{c}\text { Age } \leq 35 \\
(n=3086)\end{array}$ & $P$ value & $\begin{array}{c}\text { Age }>35 \\
(n=4807)\end{array}$ & \multirow[t]{2}{*}{$P$ value } \\
\hline & OR $(95 \% \mathrm{CI})^{2}$ & & OR $(95 \%$ CI $)$ & \\
\hline \multicolumn{5}{|l|}{ Metabolic abnormality $^{3}$} \\
\hline Yes & $1.57(0.67-3.68)$ & 0.29 & $1.29(1.07-1.59)$ & \multirow{2}{*}{0.009} \\
\hline No $(\mathrm{ref})^{4}$ & 1.00 & & 1.00 & \\
\hline \multicolumn{5}{|l|}{ Smoking habit } \\
\hline Former smoking & $3.43(1.85-5.0)$ & 0.02 & $1.49(1.05-2.05)$ & 0.02 \\
\hline Current smoking & $4(1.28-6.74)$ & $<0.0001$ & $5.29(4.00-6.66)$ & $<0.0001$ \\
\hline Nonsmoking (ref) & 1.00 & & 1.00 & \\
\hline \multicolumn{5}{|l|}{ Sex } \\
\hline Male & $2.8(1.43-4.16)$ & 0.002 & $1.9(1.5-2.33)$ & \multirow{2}{*}{$<0.0001$} \\
\hline Female (ref) & 1.00 & & 1.00 & \\
\hline $\begin{array}{l}{ }^{1} \mathrm{~A} \text { binary variable was crea } \\
{ }^{2} \text { OR: odd ratio and } 95 \% \mathrm{C} \\
\text { reference category. } \\
3 \text { "Metabolic abnormality" } \\
\text { diabetes mellitus, hyperten } \\
{ }^{4} \text { Ref: reference category. }\end{array}$ & $\begin{array}{l}\text { (i) } 0-5 \text { lost teeth a } \\
\text { interval have been } \\
\text { be present when a } \\
\text { emia. }\end{array}$ & $\begin{array}{l}\text { hary logisti } \\
\text { ass index }\end{array}$ & $\begin{array}{l}\text { category of } 0-5 \text { lost } \\
\text { e reported to have }\end{array}$ & ered as the \\
\hline
\end{tabular}

periodontitis [45]. Patients with diabetes show an increase in proinflammatory cytokines in the gingival fluid and tissues compared to periodontitis patients without diabetes [46]. The presence of periodontal pathogens in diabetic patients can initiate a cycle of tissue destruction and impaired wound healing which lead to tooth loss [47]. In addition, total tooth loss has been associated with increased levels of systolic blood pressure among Brazilian adults [48] and has been introduced as a risk indicator for hypertension in South Africa [49]. It has been suggested that periodontal disease is a possible risk factor for dyslipidemia $[50,51]$. The four elements of "metabolic abnormality" in the present study (obesity, diabetes mellitus, hypertension, and dyslipidemia) can be attributed to the major determinants of "metabolic syndrome." Therefore, it is highly suggested to perform further studies to investigate the relationship between metabolic syndrome and tooth loss and the possible mechanisms.

In the present study, the prevalence of tooth loss and its related risk factors was evaluated using a self-administrated questionnaire, which subsequently can affect the results due to probable misclassifications. Lack of clinical evaluations is another weakness of our study. Tooth loss and edentulism are highly prevalent among elderly. Since we have recruited a group of apparently healthy adults with the mean age of almost 37 years, the prevalence of these conditions in Iranian adult population may have been underestimated in the present study.

\section{Conclusion}

In the present study, we showed a high prevalence of tooth loss among Iranian adults. Aging, male gender, low level of education, cigarette smoking, and presence of metabolic abnormality can be considered as risk factors of tooth loss and edentulism. This study highlighted that among the studied potential risk factors cigarette smoking had the major impact on tooth loss. Further prospective studies are required to evaluate the possible association between metabolic syndrome and tooth loss. Community programs directed toward promoting oral health and multidisciplinary efforts are suggested for prevention of tooth loss. More longitudinal studies are needed to determine the main risk factors of tooth loss and its possible consequences among Iranian adults.

\section{Acknowledgments}

SEPAHAN was financially supported by Vice Chancellery for Research and Technology, IUMS. The authors wish to thank all staff of IUMS who kindly participated in thier study. Also, they are grateful to staff of public relations unit and other authorities of IUMS for their excellent cooperation.

\section{References}

[1] A. Sheiham and J. Steele, "Does the condition of the mouth and teeth affect the ability to eat certain foods, nutrient and dietary intake and nutritional status amongst older people?" Public Health Nutrition, vol. 4, no. 3, pp. 797-803, 2001.

[2] P. Torkzaban, "The survey of the edentulousness prevalence in population over 35 years old in hamadan in 1997," Scientific Journal of Hamadan University of Medical Sciences \& Health Services, vol. 6, no. 13, pp. 43-49, 1999.

[3] M. Z. Nassani, D. Locker, A. A. Elmesallati et al., "Dental health state utility values associated with tooth loss in two contrasting cultures," Journal of Oral Rehabilitation, vol. 36, no. 8, pp. 601609, 2009.

[4] R. M. Heath, "The dental health of elderly people in Britain, 1968 to 1988," International Dental Journal, vol. 42, no. 5, pp. 399-402, 1992. 
[5] S. Khazaei, M. S. Firouzei, S. Sadeghpour et al., "Edentulism and tooth Loss in Iran: SEPAHAN systematic review no. 6," International Journal of Preventive Medicine, vol. 3, supplement 1, pp. S42-S47, 2012.

[6] H. Hessari, M. M. Vehkalahti, M. J. Eghbal, and H. Murtomaa, "Tooth loss and prosthodontic rehabilitation among 35- to 44year-old Iranians," Journal of Oral Rehabilitation, vol. 35, no. 4, pp. 245-251, 2008.

[7] D. A. Felton, "Edentulism and comorbid factors," Texas Dental Journal, vol. 127, no. 4, pp. 389-401, 2010.

[8] World Health Organization, Oral Health Surveys: Basic Methods, World Health Organization, Geneva, Switzerland, 4th edition, 1997.

[9] A. E. Sanders, G. D. Slade, K. D. Carter, and J. F. Stewart, “Trends in prevalence of complete tooth loss among Australians, 19792002," Australian and New Zealand Journal of Public Health, vol. 28, no. 6, pp. 549-554, 2004.

[10] G. D. Slade and A. J. Spencer, "Social impact of oral conditions among older adults," Australian Dental Journal, vol. 39, no. 6, pp. 358-364, 1994.

[11] F. Müller, M. Naharro, and G. E. Carlsson, "What are the prevalence and incidence of tooth loss in the adult and elderly population in Europe?" Clinical Oral Implants Research, vol. 18, supplement 3, pp. 2-14, 2007.

[12] B. A. Burt, A. I. Ismail, E. C. Morrison, and E. D. Beltran, "Risk factors for tooth loss over a 28-year period," Journal of Dental Research, vol. 69, no. 5, pp. 1126-1130, 1990.

[13] C. McGrath and R. Bedi, "Severe tooth loss among UK adultswho goes for oral rehabilitation?" Journal of Oral Rehabilitation, vol. 29, no. 3, pp. 240-244, 2002.

[14] T. A. Dolan, G. H. Gilbert, R. P. Duncan, and U. Foerster, "Risk indicators of edentulism, partial tooth loss and prosthetic status among black and white middle-aged and older adults," Community Dentistry and Oral Epidemiology, vol. 29, no. 5, pp. 329-340, 2001.

[15] C. Susin, R. V. Oppermann, O. Haugejorden, and J. M. Albandar, "Tooth loss and associated risk indicators in an adult urban population from South Brazil," Acta Odontologica Scandinavica, vol. 63, no. 2, pp. 85-93, 2005.

[16] G. Holm, "Smoking as an additional risk for tooth loss," Journal of Periodontology, vol. 65, no. 11, pp. 996-1001, 1994.

[17] D. Armellini and J. A. von Fraunhofer, "The shortened dental arch: a review of the literature," Journal of Prosthetic Dentistry, vol. 92, no. 6, pp. 531-535, 2004.

[18] B. M. Henriksen, T. Axéll, and K. Laake, "Geographic differences in tooth loss and denture-wearing among the elderly in Norway," Community Dentistry and Oral Epidemiology, vol. 31, no. 6, pp. 403-411, 2003.

[19] R. Omar, "The evidence for prosthodontic treatment planning for older, partially dentate patients," Medical Principles and Practice, vol. 12, supplement 1, pp. 33-42, 2003.

[20] P. Adibi, A. H. Keshteli, A. Esmaillzadeh et al., "The study on the epidemiology of psychological, alimentary health and nutrition (SEPAHAN): overview of methodology," Journal of Research in Medical Sciences, vol. 17, no. 5, pp. S292-S298, 2012.

[21] N. U. Zitzmann, C. P. Marinello, E. Zemp, P. Kessler, and U. Ackermann-Liebrich, "Tooth loss, dental restorations and dental attendance in Switzerland," Schweiz Monatsschr Zahnmed, vol. 111, no. 11, pp. 1288-1294, 2001.

[22] B. G. Dogan and S. Gokalp, "Tooth loss and edentulism in the Turkish elderly," Archives of Gerontology and Geriatrics, vol. 54, no. 2, pp. e162-e166, 2012.
[23] C. A. Okoro, L. S. Balluz, P. I. Eke et al., "Tooth loss and heart disease: findings from the behavioral risk factor surveillance system," The American Journal of Preventive Medicine, vol. 29, no. 5, supplement 1, pp. 50-56, 2005.

[24] K. Edman, K. Ohrn, A. Holmlund, B. Nordstrom, M. Hedin, and D. Hellberg, "Comparison of oral status in an adult population 35-75 year of age in the county of Dalarna, Sweden in 1983 and 2008," Swedish Dental Journal, vol. 36, no. 2, pp. 6170, 2012.

[25] S. Renvert, R. E. Persson, and G. R. Persson, "Tooth loss and periodontitis in older individuals. Results from the Swedish national Study on aging and care," Journal of Periodontology, vol. 84, no. 8, pp. 1134-1144, 2013.

[26] S. Muller, P. Eickholz, P. Reitmeir, and T. Eger, "Long-term tooth loss in periodontally compromised but treated patients according to the type of prosthodontic treatment. A retrospective study," Journal of Oral Rehabilitation, vol. 40, no. 5, pp. 358367, 2013.

[27] P. Axelsson, J. Paulander, and J. Lindhe, "Relationship between smoking and dental status in 35-, 50-, 65-, and 75-year-old individuals," Journal of Clinical Periodontology, vol. 25, no. 4, pp. 297-305, 1998.

[28] B. E. Klein, R. Klein, and M. D. Knudtson, "Life-style correlates of tooth loss in an adult midwestern population," Journal of Public Health Dentistry, vol. 64, no. 3, pp. 145-150, 2004.

[29] E. Ragnarsson, S. T. Elíasson, and S. H. Olafsson, "Tobacco smoking, a factor in tooth loss in Reykjavík, Iceland," Scandinavian Journal of Dental Research, vol. 100, no. 6, pp. 322-326, 1992.

[30] M. Ojima, T. Hanioka, K. Tanaka, E. Inoshita, and H. Aoyama, "Relationship between smoking status and periodontal conditions: findings from national databases in Japan," Journal of Periodontal Research, vol. 41, no. 6, pp. 573-579, 2006.

[31] M. Ojima, T. Hanioka, K. Tanaka, and H. Aoyama, "Cigarette smoking and tooth loss experience among young adults: a national record linkage study," BMC Public Health, vol. 7, article 313, 2007.

[32] K. Tanaka, Y. Miyake, S. Sasaki et al., "Active and passive smoking and tooth loss in Japanese women: baseline data from the Osaka maternal and child health study," Annals of Epidemiology, vol. 15, no. 5, pp. 358-364, 2005.

[33] P. Ylöstalo, T. Sakki, J. Laitinen, M.-R. Järvelin, and M. Knuuttila, "The relation of tobacco smoking to tooth loss among young adults," European Journal of Oral Sciences, vol. 112, no. 2, pp. 121-126, 2004.

[34] T. Dietrich, N. N. Maserejian, K. J. Joshipura, E. A. Krall, and R. I. Garcia, "Tobacco use and incidence of tooth loss among US male health professionals," Journal of Dental Research, vol. 86, no. 4, pp. 373-377, 2007.

[35] W. M. Edgar, "Saliva and dental health. Clinical implications of saliva: report of a consensus meeting," The British Dental Journal, vol. 169, no. 3-4, pp. 96-98, 1990.

[36] I. D. Mandel, "The role of saliva in maintaining oral homeostasis," The Journal of the American Dental Association, vol. 119, no. 2, pp. 298-304, 1989.

[37] U. Heintze, "Secretion rate, buffer effect and number of lactobacilli and streptococcus mutans of whole saliva of cigarette smokers and nonsmokers," Scandinavian Journal of Dental Research, vol. 92, no. 4, pp. 294-301, 1984.

[38] G. Rajabizadeh, M. A. Ramezani, H. Roohafza et al., "Association between cigarette smoking and socio-emographics, 
lifestyle and mental health factors in a sampled Iranian population," Southeast Asian Journal of Tropical Medicine and Public Health, vol. 42, no. 4, pp. 977-987, 2011.

[39] F. Mack, N. Abeygunawardhana, T. Mundt et al., “The factors associated with body mass index in adults from the study of health in Pomerania (SHIP-0), Germany," Journal of Physiology and Pharmacology, vol. 59, supplement 5, pp. 5-16, 2008.

[40] S. Kazemi, G. Savabi, S. Khazaei et al., "Association between food intake and oral health in elderly: SEPAHAN systematic review no. 8," Journal of Dental Research, vol. 8, supplement 1 , pp. S15-S20, 2011.

[41] K. Okada, H. Enoki, S. Izawa, A. Iguchi, and M. Kuzuya, "Association between masticatory performance and anthropometric measurements and nutritional status in the elderly," Geriatrics and Gerontology International, vol. 10, no. 1, pp. 56-63, 2010.

[42] T. L. do Nascimento, D. D. da Silva, N. A. Liberalesso, H. J. Balbinot, H. F. Neves, and L. de Sousa Mda, "Association between underweight and overweight/obesity with oral health among independently living Brazilian elderly," Nutrition, vol. 29, no. 1, pp. 152-157, 2013.

[43] A. L. Ostberg, C. Bengtsson, L. Lissner, and M. Hakeberg, "Oral health and obesity indicators," BMC Oral Health, vol. 12, article 50, 2012.

[44] J. B. Hilgert, F. N. Hugo, M. L. de Sousa, and M. C. Bozzetti, "Oral status and its association with obesity in Southern Brazilian older people," Gerodontology, vol. 26, no. 1, pp. 46-52, 2009.

[45] D. Kinane and P. Bouchard, "Periodontal diseases and health: consensus report of the sixth European workshop on periodontology," Journal of Clinical Periodontology, vol. 35, no. 8, supplement, pp. 333-337, 2008.

[46] A. M. Iacopino and C. W. Cutler, "Pathophysiological relationships between periodontitis and systemic disease: recent concepts involving serum lipids," Journal of Periodontology, vol. 71, no. 8, pp. 1375-1384, 2000.

[47] M. Jimenez, F. B. Hu, M. Marino, Y. Li, and K. J. Joshipura, “Type 2 diabetes mellitus and 20 year incidence of periodontitis and tooth loss," Diabetes Research and Clinical Practice, vol. 98, no. 3, pp. 494-500, 2012.

[48] M. A. Peres, G. Tsakos, P. R. Barbato, D. A. Silva, and K. G. Peres, "Tooth loss is associated with increased blood pressure in adults-a multidisciplinary population-based study," Journal of Clinical Periodontology, vol. 39, no. 9, pp. 824-833, 2012.

[49] O. A. Ayo-Yusuf and I. J. Ayo-Yusuf, "Association of tooth loss with hypertension," South African Medical Journal, vol. 98, no. 5, pp. 381-385, 2008.

[50] T. Saito and Y. Shimazaki, "Metabolic disorders related to obesity and periodontal disease," Periodontology 2000, vol. 43, no. 1, pp. 254-266, 2007.

[51] T. Furukawa, K. Wakai, K. Yamanouchi et al., "Associations of periodontal damage and tooth loss with atherogenic factors among patients with type 2 diabetes mellitus," Internal Medicine, vol. 46, no. 17, pp. 1359-1364, 2007. 


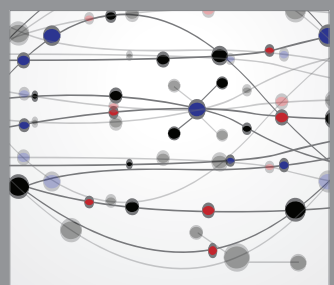

The Scientific World Journal
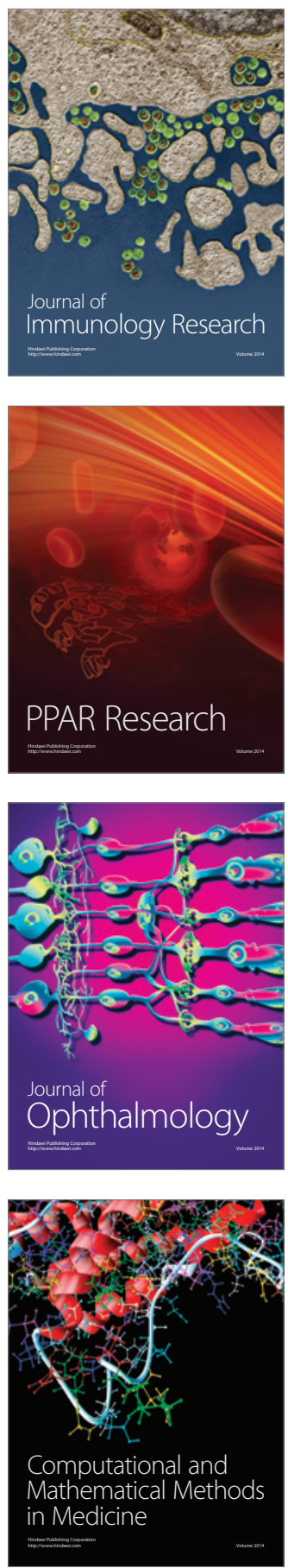

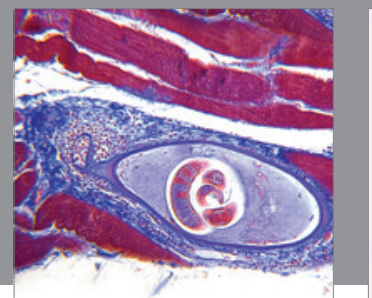

Gastroenterology

Research and Practice
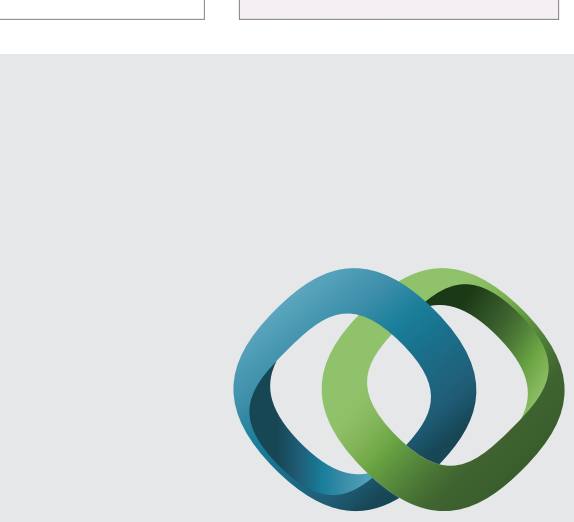

\section{Hindawi}

Submit your manuscripts at

http://www.hindawi.com
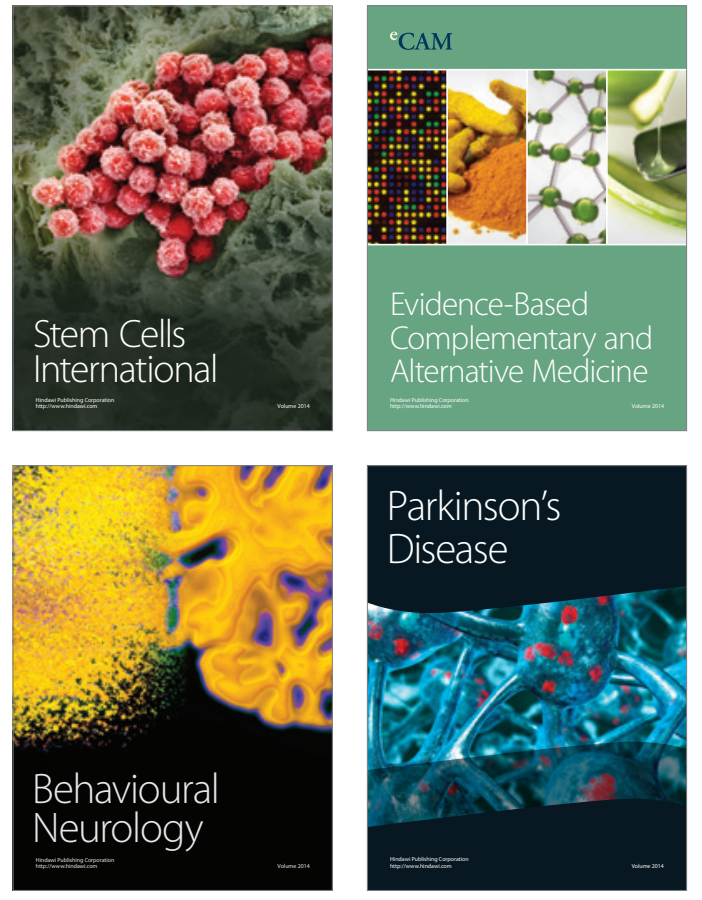
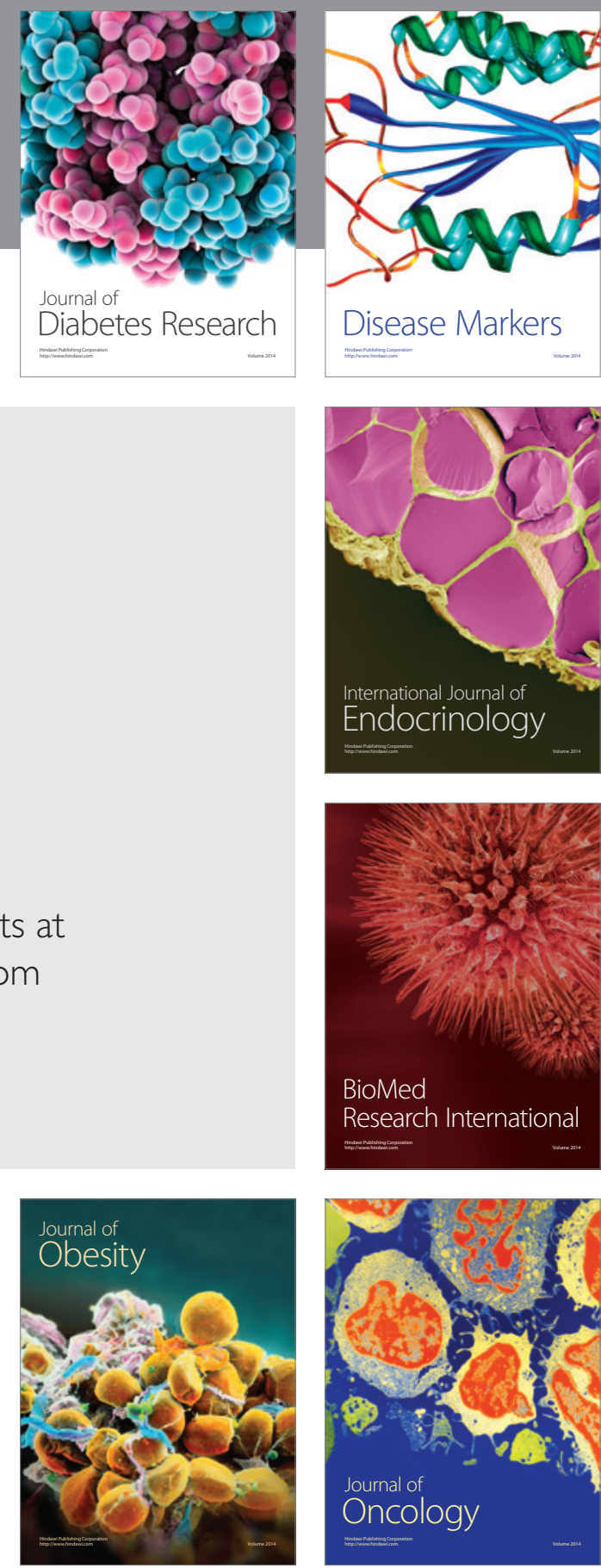

Disease Markers
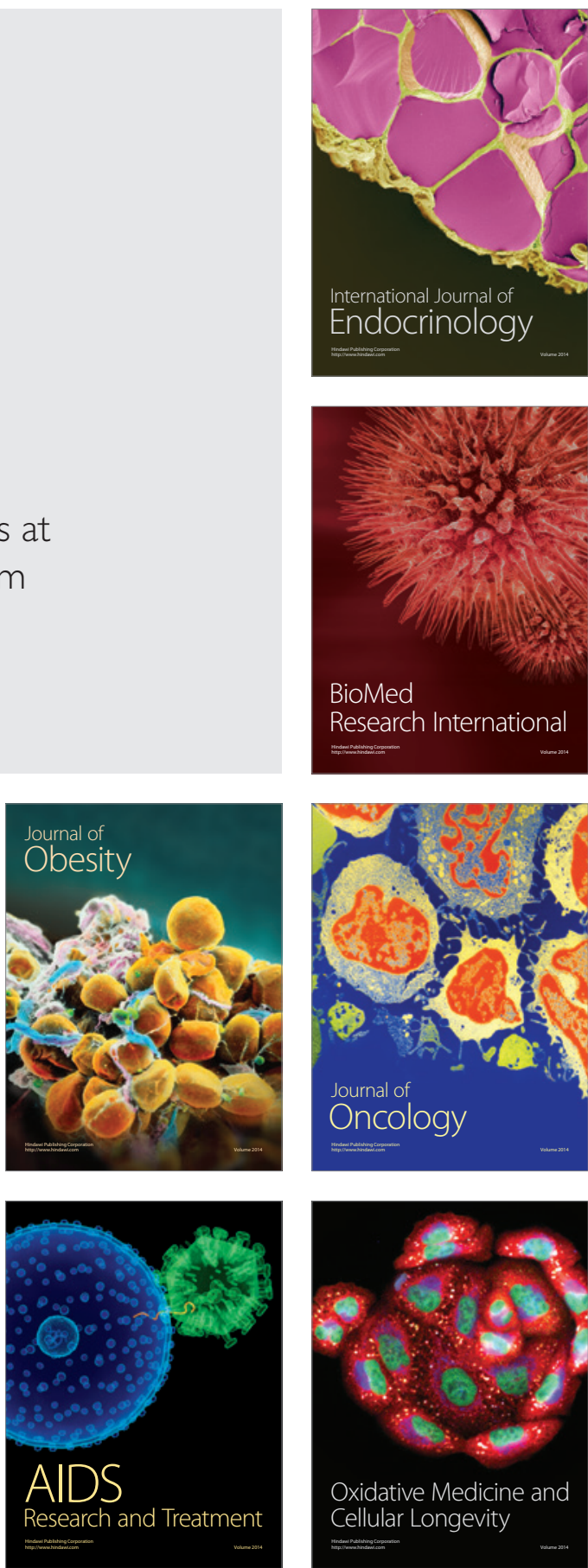